\title{
Expectations of Trustworthiness in Cross-Status Interactions
}

\author{
Running Heads: \\ Expectations of Trustworthiness
}

\author{
Mauricio Salgado \\ School of Social Sciences, Faculty of Education and Social Sciences \\ Universidad Andres Bello \\ Av. República 252, Santiago \\ Chile-m.salgado@unab.cl \\ Javier Núñez \\ Department of Economics, Faculty of Economics and Business \\ Universidad de Chile \\ Chile-jnunez@fen.uchile.cl
}

Bernardo Mackenna

Sociology Department

University of California San Diego

The United States of America - bmackenn@ucsd.edu

Keywords: trust, vignette experiments, pro-social behavior, socioeconomic status

Word count: 10388

Manuscript accepted for publication in the journal Social Science Research (May 17, 2021) 


\title{
Expectations of Trustworthiness in Cross-Status Interactions
}

\begin{abstract}
Although the literature on trust is vast, little is known about the attributes that trigger or inhibit trusting others we do not know. Using a vignette version of the trust game, we addressed the role that social standing plays in estimating trustworthiness of strangers in cross-status interactions in Chile, a non-WEIRD context also characterized by high inequality and social segregation. We found no relationship between the socioeconomic status of trustors and trusting behavior. However, trustees' income was the most important attribute for trustors to decide how much to trust. We also found that higher-income trustees are less trusted in general, particularly by lower-status trustors. Finally, the results revealed that the influence of income differences on trust was higher for lowerstatus participants: they are more trustful of others of similar status. We did not observe a similar effect of ingroup favoritism on trust among higher-status participants. These results suggest that income differences are decisive in the trust decisions of lower-status individuals.
\end{abstract}

\section{Introduction}

In a world of increasing income inequality, the normative expectations of people from different status groups may collide, weakening the social fabric and making social cooperation more difficult (Elgar \& Aitken, 2011; Putnam, 2001; Uslaner \& Brown, 2005). Status hierarchies create material and normative boundaries between groups (Lamont, 2002), hence individual status characteristics could elicit different expectations of normative behavior. In this paper we address the relationship between social status and expectations of trustworthiness. In trusting others, one party, the trustor, makes itself vulnerable by taking a course of action that creates incentives for the other party, the trustee, to exploit it. If there is no vulnerability -some risk of being disappointed in relationships with othersthen trust is not necessary (Rousseau et al., 1998). Trust is thus 'calculative', based on the expectation of trustworthiness (Hardin, 2002). Following Robbins (2016a, 2016b), we understand trust as a belief about another person's trustworthiness with respect to a particular matter at hand that emerges under conditions of uncertainty. Because this expectation is a risky belief about the future behavior of trustees (will they reciprocate?) in interactions with strangers, trustors may use social cues to infer (attribute) trustworthiness, such as phenotypical traits and markers of economic, cultural or symbolic capital. Indeed, some authors have claimed that ingroup vs. outgroup preferences and stereotyping are two social categorization mechanisms based on visible cues that lead to initial trust (how trust forms in the initial phase of a relationship, i.e. when parties are unfamiliar with each other, see McKnight \& Chervany, 2006). Evidently, social cues relate to cognitive schemata (e.g., social identities, heuristics, stereotypes) that are not central to the definition of trust, but rather causal variables that impact the willingness to trust people we do not know very well. Here, we address the role of individual differences in estimating trustworthiness, and how the trustee's characteristics are assessed by respondents of different social backgrounds when deciding to trust others. We focus on whether the social status of trustees moderates the relationship between the social status of trustors and their trusting behavior.

Material conditions of life lead to behavioral dispositions that are often not idiosyncratic but shared by people in similar conditions. Status differences also shape the normative behavior of individuals and their expectations regarding the normative behavior of others. For instance, lower-status individuals exhibit more generosity and tend to react more sympathetically to the suffering of others than higher-status individuals (Piff et al., 2010; Stellar et al., 2012). Due to their harsher living conditions, lower-status individuals are also more wary of social threats. Research has documented that lower-ranking participants are more generous and trusting, but they also track the hostile 
emotions of others more accurately and show more antagonistic reactivity compared to higherranking participants (Kraus et al., 2011). We analyze whether these different types of normative reasoning across the status hierarchy also result in different expectations of trustworthiness in crossstatus interactions.

We extend previous research on trust by studying how trustees' characteristics - such as phenotypic traits, gender, parental and own cultural capital, income, electoral participation and religious denomination - are assessed by participants when asked to trust unfamiliar others. We address this question using a vignette experiment (Atzmüller \& Steiner, 2010). There is a long tradition of research on trust using vignette experiments (e.g., Buskens \& Weesie, 2000; Robbins, 2017). These studies have addressed the sources of trust and trustworthiness in hypothetical social exchanges (e.g., car repair, group projects). In this paper, we implemented a vignette experiment that is a modified version of the trust game (Berg et al., 1995). The trust game involves two players, a trustor and a trustee, and trusting behavior is a measure of the willingness to take a chance that an investment will be rewarded by a stranger (Ben-Ner \& Halldorsson, 2010). In our modified game, participants act as trustors, and trustees are not real players, but individuals represented in vignettes whose characteristics are manipulated in order to elicit participants' expectations of trustworthiness, which we observe in their trusting behavior in the game. This design assumes that in interactions with strangers, individuals use status cues -markers that provide information regarding the status of others (Fişek et al., 2005) to form their expectations and consequently decide whether or not to trust them. We address two related questions. Firstly, whether the status characteristics of trustees outweigh other attributes, such as religious denomination and electoral participation, that might signal trustworthiness. Secondly, and more importantly, we explore the extent to which the status of participants interacts with the status characteristics of the trustee in shaping their trusting decisions.

In order to broaden the research agenda on trust, we implement our modified vignette-based trust game in Chile, which provides an adjudicative setting for addressing these questions. Inequality has been a structural feature of the social order in Chile (PNUD, 2017), which still has high income inequality, with a Gini index of 44.4 (World Bank 2017). Chile also exhibits low intergenerational economic mobility (Núñez \& Miranda, 2010), characterized by high elite closure (Torche, 2005), clear occupational barriers between social classes (Espinoza and Núñez 2014), and status attributions based on skin tone (Salgado \& Castillo, 2018) especially among the closed-off elite (Torres, et al. 2019). Based on previous research suggesting an inverse relationship between inequality and trust (Zmerli \& Castillo, 2015; also see Fairbrother \& Martin, 2013), it is not surprising that Chile exhibits comparatively low levels of generalized trust (Algan \& Cahuc, 2014). Our research thus broadens the understanding of the determinants of trust by focusing on a less-studied non-WEIRD (western, educated, industrialized, rich, and democratic), unequal, and segregated context.

\section{Social status and trust}

Differences in normative behavior across status groups stem from diverging forms of social cognition anchored in the material conditions faced by individuals (Kraus et al., 2012). While higher-status individuals experience ongoing socioeconomic freedom that enhances a mind-set involving increased attention to their own mental states and a solipsistic attitude, the heightened interdependence and attunement of lower-status individuals to the needs and emotions of others make them more concerned and cautious about people's intentions (Kraus et al., 2011). These distinctive sociocognitive traits have important implications for trust (Samson \& Zaleskiewicz, 2019): higher-status individuals tend to show higher generalized trust (they trust others more in general), while lower-status individuals tend to display higher relational trust, i.e. they trust ingroup members more (Fiske et al., 2012; Navarro-Carrillo et al., 2018). 
Generalized trust is an overall belief that 'most people can be trusted'. This optimism fosters social connections beyond the narrow circle of family and friends, encourages cooperation with strangers, and results in more opportunities (Granovetter, 1973; Yamagishi et al., 1998). Since higher-status individuals are generally wealthier, they can afford to maintain an optimistic view of people in general, because disappointment has less severe consequences for them. In contrast, the costs of unfavorable social interactions with strangers can be very harmful for lower-status individuals, since they could be more negatively affected by a betrayal in a social exchange (Navarro-Carrillo et al., 2018). Research has shown that there are lower levels of generalized trust in deprived contexts, which could serve as a protective mechanism against exploitation (Fiske et al., 2012). In addition, worldwide survey data using the 'standard trust measure'1 show that respondents from higher-income households tend to report higher generalized trust (Elgar \& Aitken, 2011).

Relational, interpersonal or particularized trust (Fiske et al., 2012; Uslaner, 2000) entails prioritizing the maintenance of secure relationships with specific individuals. Because such individuals are 'known,' or share similar characteristics, their behavior is predictable, so individuals can expect not to be harmed or treated unfairly. In this case, 'familiarity breeds trust' (Coleman, 1990). For instance, Fiske and colleagues found higher relational trust (and lower generalized trust) among blue-collar and low-income individuals (Fiske et al., 2012). However, when differentiating between high and low interaction partners, the empirical evidence is rather inconclusive.

Higher-status individuals might be perceived as more trustworthy by others. In line with the positive relationship between socio-economic status (SES) and generalized trust, upper-class individuals might more often believe that they are trusted by others, which - given the reciprocal nature of trust - could lead to greater trustworthiness on their part. It is also conceivable that higher-status individuals act more pro-socially toward others, as suggested by the social norm of noblesse oblige that requires those in the upper echelons of society to act benevolently (Fiddick \& Cummins, 2007). Thus, higher-status individuals might enact this social norm in everyday interactions, promoting the view and perception that they are indeed trustworthy. Lei and Vesely (2010) found ingroup favoritism only among higher-status participants; lower-status participants, in contrast, trusted higher-status individuals more. More recently, Samson (2018) established that higher-status individuals trust their peers more than lower-status individuals, whereas lower-status individuals trust dissimilar individuals more. Taken together, these findings support the prediction that in interactions with strangers, higher-status individuals are expected to be more trustworthy (due to outgroup favoritism among lower-status individuals and ingroup-favoritism among higher-status individuals). Thus, we can state our first hypothesis as:

\section{Hypothesis 1: Participants will expect higher-status individuals to be more trustworthy than lower-status individuals.}

However, it is likely that in a high inequality context, as in Chile, higher-status individuals are perceived as less trustworthy by lower-status individuals. Theoretically, those in disadvantaged positions might see the wealth of those at the top of the status hierarchy as underserved and their own position as unfair (Starmans et al., 2017). Poverty might be deemed the result of political dominance and economic exploitation, which reduce trust in the most privileged. Empirical research has shown that in cross-status interactions, only lower-status individuals express ingroup favoritism in their trusting behaviors, whereas higher-status individuals tend to trust others regardless of their social standing. Since people from lower-status groups are more relationally interdependent, they are more trustful of those who share relationships or similar characteristics (Fiske et al., 2012), exhibiting higher levels of relational trust. Tropp and colleagues (2006) found that participants from disadvantaged groups were more trusting of ingroup members, while members of advantaged groups expressed the same level of trust when interacting with ingroup and outgroup members. Simpson and colleagues (2007) documented that the vigilant mindset of lower-status individuals is more likely

\footnotetext{
1 The standard trust measure asks respondents: 'Generally speaking, would you say that most people can be
} trusted or that you can't be too careful in dealing with people?' 
to be applied to outgroup than ingroup members. More recently, Navarro-Carrillo and colleagues (2018) also found a negative correlation between social status and relational trust. These findings support the prediction that, in interactions with strangers, lower-status individuals would expect others from their own status group to be more trustworthy and those from higher-status groups to be less trustworthy, which yields our second hypothesis:

\section{Hypothesis 2: Lower-status participants will express higher relational trust than higher-status participants.}

Finally, in a trust game, the trustor could transfer resources to the trustee based not only on trust, but also on prosocial preferences such as altruism or egalitarian values, which may also be conditional to the characteristics of the trustee's status. Egalitarian trustors could therefore send more resources to lower-status trustees, even if they do not expect reciprocity. In this context it would not be the trustors' expectations of trustworthiness of the trustees that would motivate seemingly trusting behavior, but rather the status of trustees that would make them deserving (or not) of 'help'. Indeed, previous research has shown that trust decisions are related to both expectations of trustworthiness (i.e., reciprocity) and egalitarian/altruistic preferences (Ashraf et al., 2006). Ben-Ner and Halldorsson (2010) found that a substantial portion of the trusting behavior in this game captures more than just trusting, as it also reflects unconditional kindness towards others. Sapienza and colleagues (2013) understand the act of trusting as the combination of two components: belief in the trustworthiness of other people and the specific egalitarian/altruistic preferences of the trustor. Therefore, we must not only control for the distributive preferences of the trustor, but also study the moderating effect of egalitarian preferences as the underpinning factors of trusting behavior in the game, which yield the third hypothesis:

Hypothesis 3: Participants exbibiting higher egalitarian/altruistic values will send larger amounts to lower SES individuals in the trust game.

Testing this hypothesis would require not only controlling for an appropriate measure of egalitarian/altruistic values of individuals, but also for their interaction with the perceived socioeconomic status of trustees, which would be a proxy of their needs (or their marginal utility of money in economic terms, which is expected to be higher for lower-SES individuals). In synthesis, given the country's high levels of inequality, studying expectations of trustworthiness in Chile provides an adjudicative case for two opposing hypotheses: whether higher-status individuals are perceived as more trustworthy, or whether they are perceived as less trustworthy, particularly by lower-status individuals, who instead could trust others of similar status more. Both hypotheses have empirical support, so this article introduces Chile to the comparative project of researching expectations of trustworthiness in the social sciences.

\section{Data and Methods}

\section{Vignettes and Data}

A multiple-stage data collection design was implemented on a wide range of post-secondary education programs and institutions attended by students of different SES. Post-secondary education offers a setting of a transitional nature between a deeply income-segregated school system (Valenzuela et al., 2014) and entry into the labor market. Hence, the higher educational tier - albeit still significantly segregated by social class - offers exceptional socioeconomic diversity, which most individuals would not experience elsewhere in their social lives (Cabrera, 2016). It requires individuals to routinely interact with others with whom they have seldom interacted, thus making social categorization and expectations based on everyday interactions particularly relevant for understanding behavior. 
The visual stimuli for the vignettes are based on 120 photographs of students' faces taken at four post-secondary educational institutions in Santiago, Chile, paired with rich socioeconomic data from the photographees (self-reported SES information such as subjective and objective status). The details of how the visual stimuli were elaborated and selected can be found in a previous paper by the authors (Torres et al., 2019). The stimuli data comprise scores on different characteristics attributed to the photographs by different, independent samples of post-secondary education students: skin pigmentation of the photographees using the PERLA scale designed for the Latin America context (Telles, 2014); moral and emotional features (or 'functional attributes') of faces (Oosterhof \& Todorov, 2008), such as attributions of generosity, trustworthiness, attractiveness, submission, and intelligence. Also, we collected socioeconomic information attributed to the individuals portrayed in different dimensions of symbolic, economic and cultural capital. This socioeconomic information yielded a numerical vector of imputed status based on self-presentation (Goffman, 1959) for the entire sample of 120 photographs.

The vignette-based modified trust game design entailed exposing participants - who were paid a small turn-up fee (CLP1,000) - to a series of fictitious trustees (presented to them as real individuals) with a set of characteristics that were randomly rotated. In each round, participants chose how much to offer a partner (from CLP 0 to CLP 1,000), on the understanding that the trustee would receive four times the amount the participant sent. Following Stanley and colleagues (2011), participants were told that their partners were real individuals we had previously interviewed and who had already made the decision to return half or keep all of whatever amount they received. Thus, participants had to judge whether their partners in the vignette had made a mutually beneficial decision (in which case, the participants could increase their payoff) or if they had instead acted in a self-regarding way ${ }^{2}$. Each participant engaged in twelve rounds of this game with different vignettes. To evaluate potential effects due to varying comprehension of instructions across participants, they were randomly assigned to one of two framing instructions: one made explicit the risk of exploitation in deciding how much to trust ('reminding condition'), and the other did not.

In order to elaborate the visual stimuli, a subsample of 24 of the 120 photographs was selected using the following procedure: We ranked them by their self-presentation status value and then computed a score by taking the deviation of each one of the 120 photographs to a quintile or decile mean, penalized by the amount of disagreement between raters ${ }^{3}$. The four photographs with the lowest scores from the first and third quintiles, and the tenth decile were selected for each gender to represent the lower, middle, and elite (attributed) SES, respectively. The 24 selected photographs ${ }^{4}$ used in the vignettes thus correspond to six groups (2 genders x 3 SES groups).

Seven characteristics (summarized in Table 1) were used in this factorial study to create each vignette (i.e., fictitious trustee): 1) photograph; 2) post-secondary-education institution; 3) his/her mother's education; 4) his/her household income; 5) gender (implicit in the picture); 6) whether he/she voted in the last local election; and 7) his/her religious denomination. First, presentation-based features in the visual stimuli are powerful cues for status categorization of strangers in daily life (Salgado \& Castillo, 2018; Torres et al., 2019). Second, previous research indicates a significant degree of

\footnotetext{
${ }^{2}$ In order to randomly manipulate the stimuli in the vignettes, this study involved deceiving participants into thinking that the individuals presented in the vignettes were real individuals. In accordance with APA (2017) and ASA (2018) codes of ethics, participants were debriefed after the data gathering session (specifying how they were deceived), and were paid the best-scenario amount of the game to rule out any potential harm in the participants' pay-off.

${ }^{3}$ The score was estimated for each $i$ photograph as: $\left(X_{i}-\bar{X}_{l}\right)^{2}+s^{2} \alpha$, where $X_{i}$ is the mean SES attributed at stage 4 for that photograph; $\bar{X}_{l}$ is the mean SES of that group of photographs (quintile or decile), $s^{2}$ is the variance of SES attributed by classifiers, and $\alpha$ is a scaling adjustment for the variance. This score enables selecting the photographs that were more consistently classified in a certain position on the SES scale.

${ }^{4}$ Even though the selection process was conducted separately by gender, due to the particularities of the SES classification obtained from stage 4, we selected 11 female photos and 13 male photos to guarantee at least 3 photos for each sub-group (gender-SES).
} 
socioeconomic segregation in the different types of post-secondary education institutions in Chile (Cabrera, 2016): higher-status students attend more selective universities, leaving less-selective university and technical schooling centers for lower-status students; only poor students attend vocational training centers. Third, parents' education is also highly correlated with the current status of individuals, as extensive literature in the social sciences has documented. We used the education of mothers in the vignettes, since $48 \%$ of the household heads with children have no resident partner, and $72 \%$ of these single-parent households are led by women (Chilean Ministry of Social Development, 2017). Fourth, household income was presented in the vignette by ordinal income levels and not in monetary terms, based on previous research suggesting that young individuals have different perceptions of the relative position of incomes in the income distribution (Salgado, 2020). Finally, an implicit attribute in the vignettes is the gender of photographees, since it is a well-known diffuse status cue (Berger \& Fişek, 2006), and women are also expected to exhibit more prosocial behavior (Eagly, 2009; Salgado, 2018).

Table 1. Vignette Design Variables, Categories and Levels

\begin{tabular}{lcc}
\hline \hline Vignette Variable & Categories & Levels \\
\hline \hline Self-Presentation-Based Social Status & $\begin{array}{l}\text { Low, middle, and high } \\
\text { Photographee's Education }\end{array}$ & $\begin{array}{c}\text { Vocational training center, technical training } \\
\text { center, low-selectivity university, high- } \\
\text { selectivity university }\end{array}$ \\
Photographee's Mothers' Education & $\begin{array}{c}\text { Primary school only, high school only, } \\
\text { technical education, low-selectivity } \\
\text { university, high-selectivity university }\end{array}$ & 5 \\
Photographee's Household Income & Low, mid-low, middle, mid-high, and high \\
Photographee's Gender & Male, female & 5 \\
Photographee's Religion & Catholic, Evangelical, and no religion & 2 \\
Photographee's Electoral Participation & Yes, no & 3 \\
\hline \hline Total possible vignettes & & 2 \\
\hline \hline
\end{tabular}

To conceal the salience of SES measures and the purpose of our study from participants, two additional attributes unrelated to SES, but related to prosocial behavior, were added to the vignettes: electoral participation, based on evidence suggesting that it signals prosocial preferences (Aytimur et al., 2014) and willingness to participate in collective action (Ostrom, 1998); and religious denomination, which has been culturally linked to higher trustworthiness (Tan \& Vogel, 2008), particularly in Chile, where it is a signal of adherence to discipline and righteousness (Thumala Olave, 2012). The seven vignette characteristics and their corresponding levels yield a factorial survey design of 3,600 possible vignettes, as shown in Table 1.

In order to efficiently select a sample of vignettes (Dülmer, 2007), those deemed to be implausible were removed from the full factorial design, and then a sample of vignettes with uncorrelated dimensions was obtained using the AlgDesign package of $\mathrm{R}$ (Wheeler, 2019) through the G-efficiency parameter, which ranges from 0 (inefficient design) to 1 (efficient design). The resulting design of 120 vignettes had a G-efficiency of 0.96 . Finally, the selected combinations were randomly sampled and grouped into 10 subsets (called decks) of 12 vignettes, to guarantee that participants were not exposed more than once to the same photograph paired with different attributes. These subsets were randomly assigned to participants and administered in lab-in-the-field experimental sessions through tablets or computers using oTree (Chen et al., 2016). We presented the vignettes in tabular format, and the position of each feature (except for the picture, which was always on top) was randomized between participants. 
We carried out two sessions each in four locations: a high and a low-selectivity university (University $A$ and $B$ respectively), a technical training center, and a vocational training program (the same spectrum of post-secondary education institutions from which the photographs in the stimuli were taken). Two sessions of 30 participants, each with different framing instructions, were conducted in each institution. In total, 2,880 trusting decisions were recorded (240 participants x 12 decisions). The oTree platform also included a social value orientation scale (see below), a comprehension test of the trust game, the vignette trust experiment, and a short sociodemographic questionnaire (in that order). Sessions were personally monitored by the authors and trained assistants.

\section{Variables}

The measure of trust is the amount of money that participants send to the trustees presented in the vignettes (amount sent). Since each participant faced 12 different vignettes, it encompasses two levels of analysis. The first level - trustees' characteristics - involves the factorial survey itself, which manipulates the seven attributes presented in Table 1. Given the advantages of vignette studies, this design allowed us to estimate the specific weight that these features have on expectations of trustworthiness. Besides, we controlled for the information on trustees' pictures and scores on the attributes imputed to these pictures (see above): gender (present in the picture), the PERLA skin pigmentation scores, objective and subjective status, generosity, trustworthiness, attractiveness, submission, and intelligence. Descriptive statistics for these measures are available in Appendix 1.

The second level of analysis -trustors' characteristics- involves two main variables: the standardized measure of the SES of participants, and their social values orientation (SVO). The SES of participants is the standardized mean of the maximum educational level (which contains 10 ordinal categories: 'no education' $=1$; 'incomplete primary education' $=2$; 'complete primary education' $=3$; 'incomplete high school' $=4$; 'complete high school' $=5$; 'incomplete technical training center' $=6$; 'complete technical training center' $=7$; 'incomplete university' $=8$; 'complete university' $=9$; 'Postgraduate' $=$ 10) and occupational status (open-ended question) ${ }^{5}$ achieved by their parents ${ }^{6}$ (we codified all reported occupations using the International Standard Classification of Occupations, ISCO-08, see International Labour Organization, 2012). The SVO of participants is obtained from the Social Values Orientation scale responded by participants prior to the experiment, a well-validated measure of the significance of own and others' welfare (Balliet et al., 2009). Following Piff et al., (2010), participants were told they were playing a game with a person known as 'the other' and were then presented with nine consecutive scenarios where they decided to allocate points to themselves or to the other, with more points being beneficial for respondents. For each scenario, participants chose from three options: a competitive option, in which participants gave the fewest points to the other while keeping a moderate number of points for themselves; an individualistic option, in which participants gave a moderate number of points to their partner while giving themselves the highest number of points; and a cooperative or egalitarian option, in which participants gave an equally moderate number to themselves and their partners. The SVO measure was indexed as the sum of all the trials in which participants chose the egalitarian option (ranging from 0 to 9 ) and then rescaled it to a 0 to 1 range, with higher scores indicating greater egalitarian/altruistic social values. We also controlled for participants' gender, age, religious denomination (catholic, evangelical or none), electoral participation in the last election (yes or no), their response to the standard trust measure (Generally speaking, would you say that most people can be trusted or that you can't be too careful in dealing with

\footnotetext{
5 The indicators were combined for conceptual clarity and reducing collinearity (correlation $r=0.712$ ) yielding a reliable scale (Cronbach's $\alpha=0.823$ ). Robustness checks using the individual variables produced no significant changes and are available from the authors upon request.

${ }^{6}$ It was not possible to have matching SES measures for trustors and trustees. Since household income has a high non-response rate among young adults attending post-secondary education, we opted instead to request parents' education and occupation as more reliable proxies for long-term income. We opted for household income measures of vignettes/trustees, as they depict hierarchical structure more clearly and univocally than occupations.
} 
people?), from 0 (= 'need to be very careful in dealing with people') to 10 (= 'most people can be trusted') as recommended by Lundmark and colleagues (2016), and a measure of individual risk attitudes (How willing are you to take risks, in general?, see Dohmen et al., 2011), in which respondents rated their willingness to take risks on a scale from 1 (= 'not at all willing') to 10 (= 'very willing'). Descriptive statistics for participant level data is available in Appendix 2. The two types of instructions implemented were also controlled in the empirical analysis.

\section{Empirical Strategy}

Following the standard practice for analyzing factorial survey experiments (Auspurg \& Hinz, 2014), the nested nature of our repeated measurements (i.e., vignette evaluations nested within participants) was considered for testing the hypotheses, thus estimating a set of multilevel linear regression models (Gelman \& Hill, 2006). A first random intercept ${ }^{7}$ model can be specified by the following equation:

$$
\text { (1) } T_{i j}=\alpha_{j}+\sum_{k} \beta_{k} X_{i j}^{k}+\sum_{m} \gamma_{m} W_{j}^{m}+e_{i j}+\mu_{i j}
$$

Where $T_{i j}$ is the amount sent in the trust game for the participant $j$ at evaluation $i ; \sum_{k} \beta_{k} X_{i j}^{k}$ is the sum of all the $k$ vignette-level predictors' coefficients $\left(\beta_{k}\right)$ times their observed values for participant $j$ at evaluation $i$ for the $k$ variable $\left(X_{i j}^{k}\right) ; \sum_{m} \gamma_{m} W_{j}^{m}$ is the sum of all the $m$ participant-level predictors' coefficients $\left(\gamma_{m}\right)$ times the observed values for participant $j$ at variable $m$, and $e_{i j}$ and $\mu_{i j}$ are vignette and participant-level errors, respectively. This first specification allows testing the relationship between the vignette features and participants' characteristics on the amounts sent, and thus relates to hypothesis 1.

A second model expands on the first one by adding a set of interaction effects between the vignette status-related coefficients and the participants' SES attributes, to test hypothesis 2 regarding relational trust, where $V_{i j}^{n}$ is the $n$ vignette-status attribute for evaluation $i$ of participant $j$; SES is the socioeconomic status of participant $j$, and $\delta_{n}$ is the associated interaction coefficient:

$$
\text { (2) } T_{i j}=\alpha_{j}+\sum_{k} \beta_{k} X_{i j}^{k}+\sum_{m} \gamma_{m} W_{j}^{m}+\sum_{n} \delta_{n}\left(V_{i j}^{n} * S E S_{j}\right)+e_{i j}+\mu_{i j}
$$

Finally, a third model ${ }^{8}$ seeks to clarify the relation between vignette status-related features and participants' amount sent by testing the moderating effect of egalitarianism (whether the relation between vignette status-related features and the amount sent varies by SVO), predicted by hypothesis 3, using a formulation similar to Equation 2, replacing SES for SVO, such as:

$$
\text { (3) } T_{i j}=\alpha_{j}+\sum_{k} \beta_{k} X_{i j}^{k}+\sum_{m} \gamma_{m} W_{j}^{m}+\sum_{n} \delta_{n}\left(V_{i j}^{n} * S V O_{j}\right)+e_{i j}+\mu_{i j}
$$

To facilitate interpretation of results, the predicted amount sent was estimated with $95 \%$ confidence intervals via the delta method and plotted by vignette status features, SES, and SVO.

\section{Results}

Our sample data reproduce the previously established positive correlation between the SES of individuals and the standard trust measure. Indeed, as shown in Figure 1, higher-status participants showed, on average, higher levels of generalized trust, $\beta=0.528, p=0.002$. As previous research has

\footnotetext{
${ }^{7}$ Random slopes specifications were also estimated for SES and SVO, with no relevant differences from results presented, and are available from the authors upon request.

8 An additional fourth model with both interactions in tandem yielded similar results and it is available in
} Appendix 3. 
claimed (Simpson et al., 2007), this result makes the experimental analysis presented here more convincing. We now turn to the analysis of the amount sent in the modified trust game.

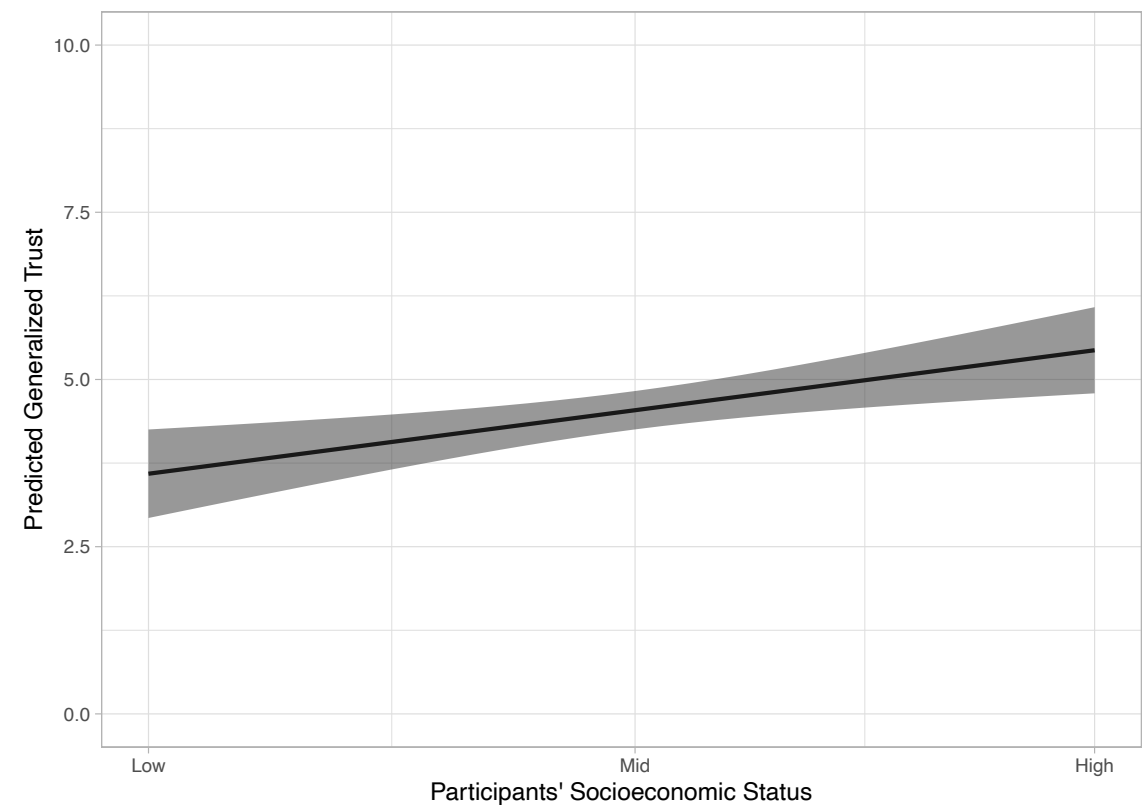

Figure 1. Predicted Generalized Trust by participant's social status. Lines represent point estimates. Shaded areas represent $95 \%$ confidence intervals.

The average amount sent, CLP534 (SD = CLP293), is nearly half of the endowment (CLP1,000). However, participants who were reminded by the instructions that the vignette-trustee had no obligation to correspond their trust, sent an average amount of CLP477 (SD = CLP289), as opposed to the mean of CLP590 (SD = CLP286) when the other framing was applied. A dummy variable identifying the randomly assigned instructions was included in the regressions9. As shown in Error! Reference source not found., both groups share similar distributions, with a peak around CLP500.

\footnotetext{
9 Our main conclusions hold the same when running the models with each data subset. Partial estimates are available from the authors on request.
} 


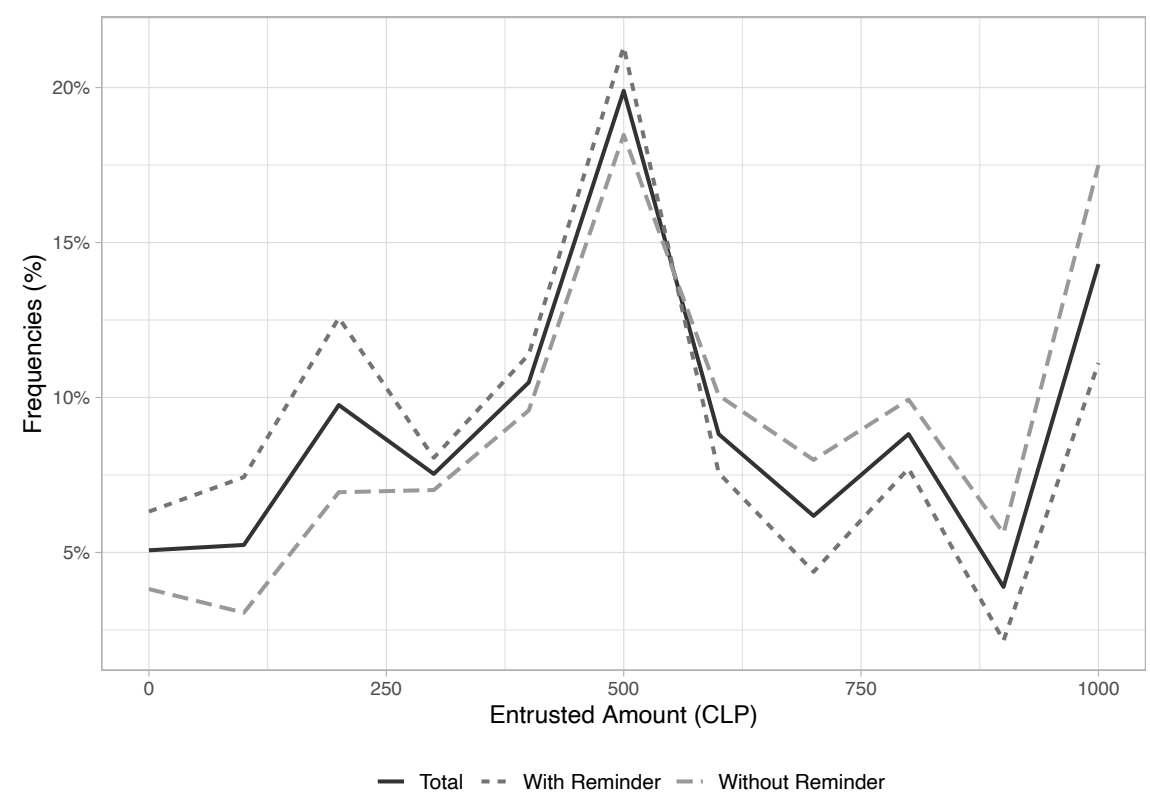

Figure 2. Distribution of amounts entrusted by participants in vignette experiment, based on instructional framing received.

Table 2Appendix 3. Complete multi-level regression models of trusted amount in vignette experiment. presents a reduced version (controls included but omitted for space constraints) of the estimates from the three models specified earlier (Appendix $\mathbf{3}$ includes complete versions of these results). Models fit the data moderately well and the second specification including the moderating effects between participants' and their partners' SES fits best in terms of Snijders and Bosker's (1994) $\mathrm{R}^{2}$ and AIC, but BIC's heavier penalization of additional parameters (Raftery, 1995) suggests the first specification by a small margin $(\triangle \mathrm{BIC}<1)$. The three goodness-of-fit statistics suggest that the third specification (which tests alternative hypothesis 3 ) has the lowest predictive power.

All specifications yield a robust difference of 84 fewer CLPs sent by participants who were reminded that their partners (i.e., trustees) might betray them, compared to the group that was not reminded, consistent with the descriptive data above. Table 2 shows the robust effect of the declared generalized trust of participants in the approximately 27 CLP greater amount sent per additional point in the standard trust measure, consistent with previous evidence (Ermisch et al., 2009; Johnson \& Mislin, 2012). There is also a positive and significant relation between risk attitudes and the amount sent, as expected.

Regarding participants' (first-level) attributes, we find that contrary to previous works (Piff et al., 2010), the SES of participants is not associated with the amount they sent in the game (see Table 2), as all specifications yield a small and non-significant coefficient. However, there is a positive and significant association between participants' social values orientation (SVO) and the amount of money they sent, as in Piff et al., (2010): more egalitarian/altruistic individuals tended to send significantly larger amounts.

Regarding vignette-trustee (second-level) attributes, Table 2 shows that the electoral participation of trustees yielded a positive and robust effect on amounts sent by participants, of around 30 CLP more to vignette-trustees acknowledging participation in the last local elections. However, the declared voter turnout of participants does not make a discernible difference in the entrusted amounts. Finally, religious denomination had no impact on the participants' expectations of trustworthiness. 
Table 2. Multilevel regression models of trusted amount in vignette experiment.

\begin{tabular}{|c|c|c|c|c|c|c|c|}
\hline \multicolumn{2}{|r|}{ Model } & \multicolumn{2}{|c|}{ (1) } & \multicolumn{2}{|c|}{ (2) } & \multicolumn{2}{|c|}{ (3) } \\
\hline Source & Variable & Coef. & $(\mathrm{SE})$ & Coef. & $(\mathrm{SE})$ & Coef. & $(\mathrm{SE})$ \\
\hline \multirow{5}{*}{$\begin{array}{c}\text { Vignette: } \\
\text { Trustee } \\
\text { Level }\end{array}$} & "Home Income: Mid-Low & $-43.421 * *$ & (12.024) & $-42.935 * *$ & (11.958) & $-53.159 *$ & (22.035) \\
\hline & Home Income: Mid & $-42.656 * *$ & $(12.562)$ & $-42.714 * *$ & $(12.495)$ & -16.479 & $(21.931)$ \\
\hline & Home Income: Mid-High & $-110.722^{* *}$ & $(11.156)$ & $-109.973^{* *}$ & $(11.096)$ & $-128.486^{* *}$ & $(20.844)$ \\
\hline & Home Income: High & $-143.569 * *$ & $(12.197)$ & $-142.814^{* *}$ & $(12.130)$ & $-157.762 * *$ & $(21.987)$ \\
\hline & Electoral Participation & $29.653^{* *}$ & $(7.404)$ & $28.887 * *$ & $(7.366)$ & $29.965^{* *}$ & $(7.395)$ \\
\hline \multirow{5}{*}{$\begin{array}{c}\text { Participant } \\
\text { Level }\end{array}$} & Socioeconomic Status (SES) & 6.440 & $(18.092)$ & -29.088 & $(19.540)$ & 6.186 & $(18.114)$ \\
\hline & Electoral Participation & 15.221 & $(26.357)$ & 14.475 & $(26.287)$ & 14.818 & $(26.390)$ \\
\hline & Generalized Trust & $27.214^{* *}$ & $(5.919)$ & $27.351 * *$ & $(5.903)$ & $27.327 * *$ & $(5.926)$ \\
\hline & Generalized Risk & $24.189 * *$ & $(7.929)$ & $23.976^{* *}$ & $(7.908)$ & $24.215^{* *}$ & $(7.938)$ \\
\hline & Social Values Orientation (SVO) & $76.900^{*}$ & (36.194) & $75.982 *$ & $(36.097)$ & 71.788 & $(40.794)$ \\
\hline Design & Reminder & $-83.618^{* *}$ & $(27.223)$ & $-84.795^{* *}$ & $(27.151)$ & $-83.760 * *$ & $(27.258)$ \\
\hline \multirow{14}{*}{$\begin{array}{c}\text { Interaction } \\
\text { Effects }\end{array}$} & HI: Mid-Low $*$ SES & & & $34.880^{* *}$ & $(12.231)$ & & \\
\hline & HI: Mid $*$ SES & & & $30.209 *$ & $(12.004)$ & & \\
\hline & HI: Mid-High $*$ SES & & & $55.359 * *$ & $(11.594)$ & & \\
\hline & HI: Mid-Low * SVO & & & & & 15.839 & $(30.084)$ \\
\hline & HI: Mid * SVO & & & & & -42.113 & $(29.133)$ \\
\hline & HI: Mid-High * SVO & & & & & 28.959 & $(28.535)$ \\
\hline & HI: High $*$ SVO & & & & & 22.819 & $(29.588)$ \\
\hline & Intercept & -50.093 & $(208.847)$ & -37.467 & $(207.947)$ & -49.862 & $(209.128)$ \\
\hline & Evaluation-level R² & \multicolumn{2}{|c|}{0.2041} & \multicolumn{2}{|c|}{0.2104} & \multicolumn{2}{|c|}{0.2041} \\
\hline & Participant-level $\mathrm{R}^{2}$ & \multicolumn{2}{|c|}{0.2683} & \multicolumn{2}{|c|}{0.2723} & \multicolumn{2}{|c|}{0.2666} \\
\hline & AIC & \multicolumn{2}{|c|}{38808} & \multicolumn{2}{|c|}{38784} & \multicolumn{2}{|c|}{38808} \\
\hline & $\mathrm{BIC}$ & \multicolumn{2}{|c|}{39058} & \multicolumn{2}{|c|}{39059} & \multicolumn{2}{|c|}{39082} \\
\hline & Evaluations & \multicolumn{2}{|c|}{2,880} & \multicolumn{2}{|c|}{2,880} & \multicolumn{2}{|c|}{2,880} \\
\hline & Participants & \multicolumn{2}{|c|}{240} & \multicolumn{2}{|c|}{240} & \multicolumn{2}{|c|}{240} \\
\hline
\end{tabular}

Notes: Non-standardized coefficients and multi-level standard errors reported (in parentheses). Controls included in the estimate but omitted due to space constraints. $\mathrm{R}^{2}$ estimated using Snijders and Bosker approach (1994). Full results available in Appendix 3. ${ }^{*} p<0.05,{ }^{* *} p<0.01$.

Among the status cues in the vignettes, only household income (HI) had a significant impact on participants' decisions (see Appendix 3). As shown in Figure 3, the higher the HI presented in the vignette, the lower the amount sent to the fictitious trustee. Not only are the corresponding coefficients highly significant, but the scale of their effects is among the largest in our estimates. This result contradicts hypothesis 1: higher SES vignettes (represented via HI) are deemed less trustworthy. However, the results are not entirely linear: although the least trusted groups were the 'High' and 'Mid-High' HIs and the most trusted was the 'Low' HI, the 'Mid-Low' and 'Mid' received statistically similar amounts. 


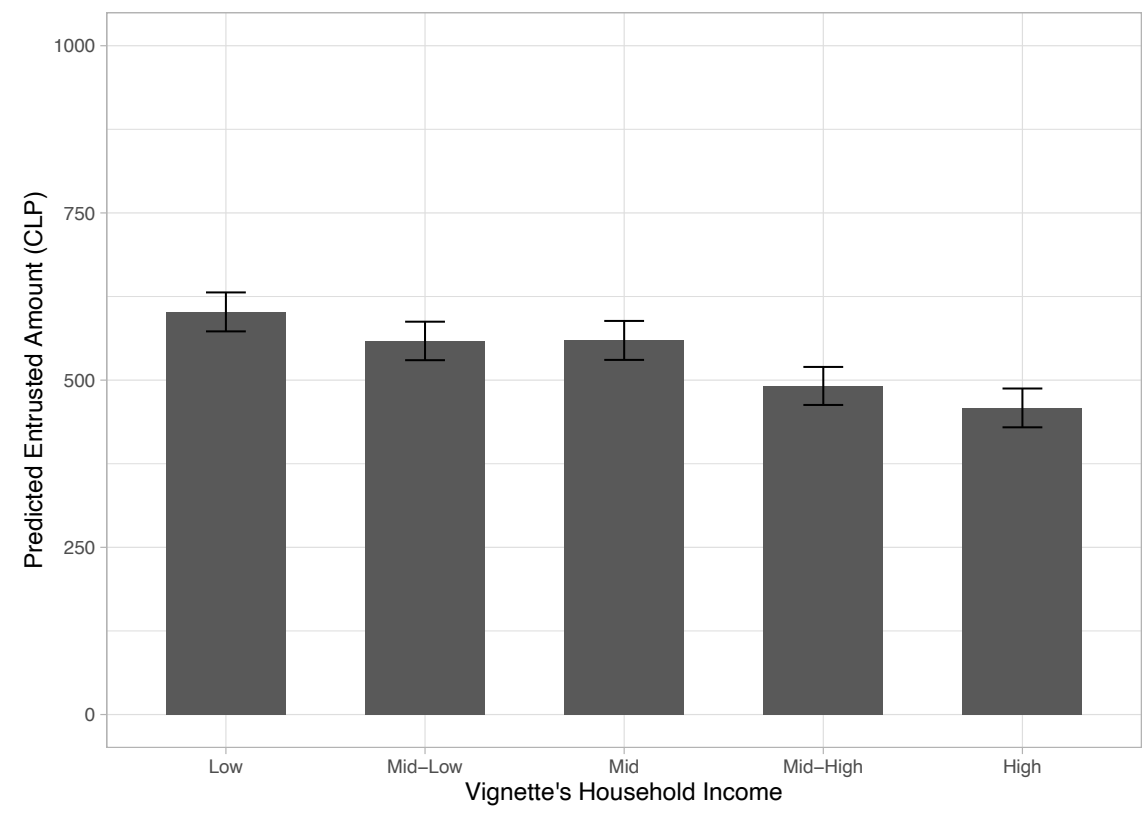

Figure 3. Predicted amounts entrusted by the household income of vignettes. Estimated from Model 1 in Table 2. Bars represent point estimates; brackets represent 95\% confidence intervals.

Are high-income vignettes less trusted because of relational trust among lower-status individuals, as stated in hypothesis 2 ? Or, do low-income trustees receive larger amounts as a form of redistribution due to egalitarian/altruistic values, as predicted by alternative hypothesis 3 ? The interaction effects between the HI dummies and participants' SES in Model 2 (see Table 2) suggest that the trustworthiness attributed by individuals to the SES groups varies significantly with respect to the SES of trustors/participants. To facilitate interpretation, Figure 4 presents the predicted amounts sent from Model 2, based on the SES of the participants, for both High-HI and Low-HI presented in the vignettes. 


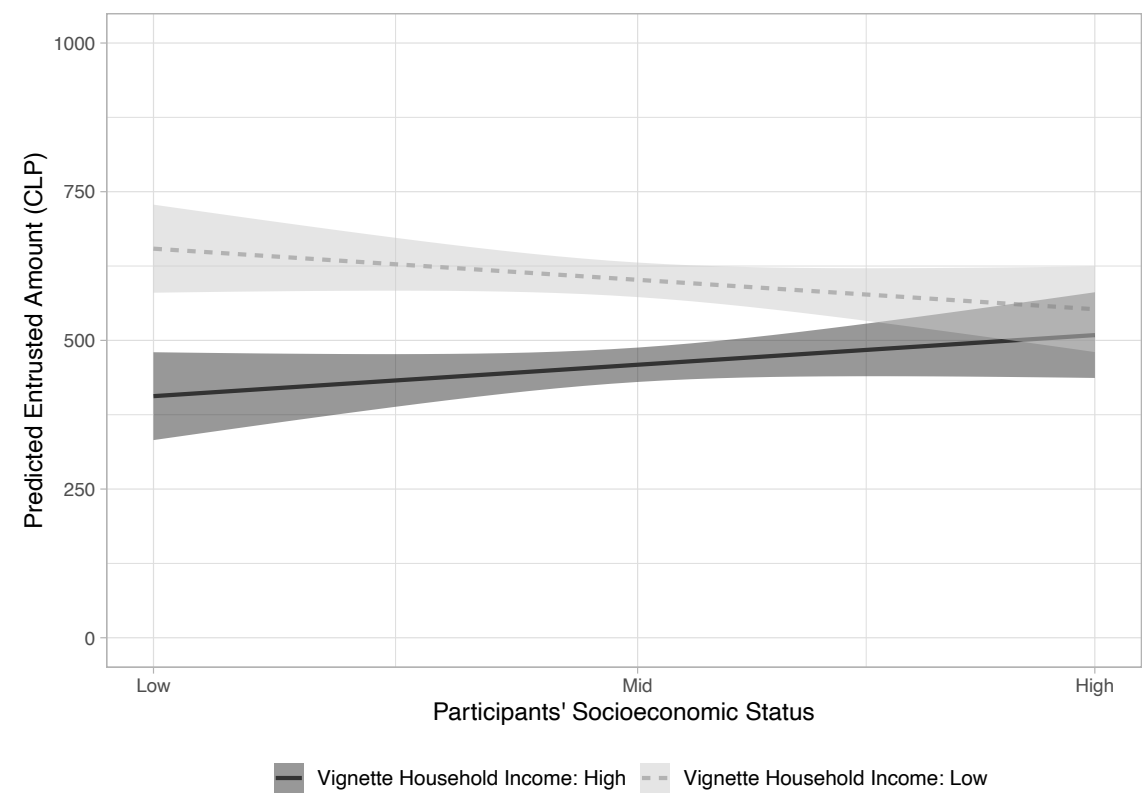

Figure 4. Predicted amount entrusted, by vignette's household income and participant's social status. Estimated from Model 2 in Table 2. Lines represent point estimates. Shaded areas represent 95\% confidence intervals.

Figure 4 indicates that while lower-SES participants sent significantly more to low-HI vignettes than to high-HI vignettes, as we move on to higher-SES participants, the gap in the amount of money sent to high and low-HI vignettes diminishes, until no statistical difference can be established between these two extreme HI groups among the highest SES participants. This outcome supports hypothesis 2 , since we only find ingroup favoritism among the low-SES participants, whereas higher-SES individuals seem indifferent to their counterparts' HI.

Regarding alternative hypothesis 3 (i.e., participants might send more money to vignettes with lower HI due to preferences for redistribution or altruism), Model 3 incorporates an interaction effect between the egalitarian/altruistic values of participants (as measured by the SVO scale) and HI of vignettes, which did not reach conventional levels of statistical significance (see Table 2). Again, for simplicity, Error! Reference source not found. shows the predicted amount sent to low-HI and highHI vignettes. The results lend no support to hypothesis 3: there is no statistical difference between the amounts sent to low-HI individuals along the entire SVO spectrum. We found that even though participants still sent high-HI counterparts noticeably less money than to low-HI ones, this difference is constant across the different SVO levels of participants. This complementary evidence lends further support to hypothesis 2 . 


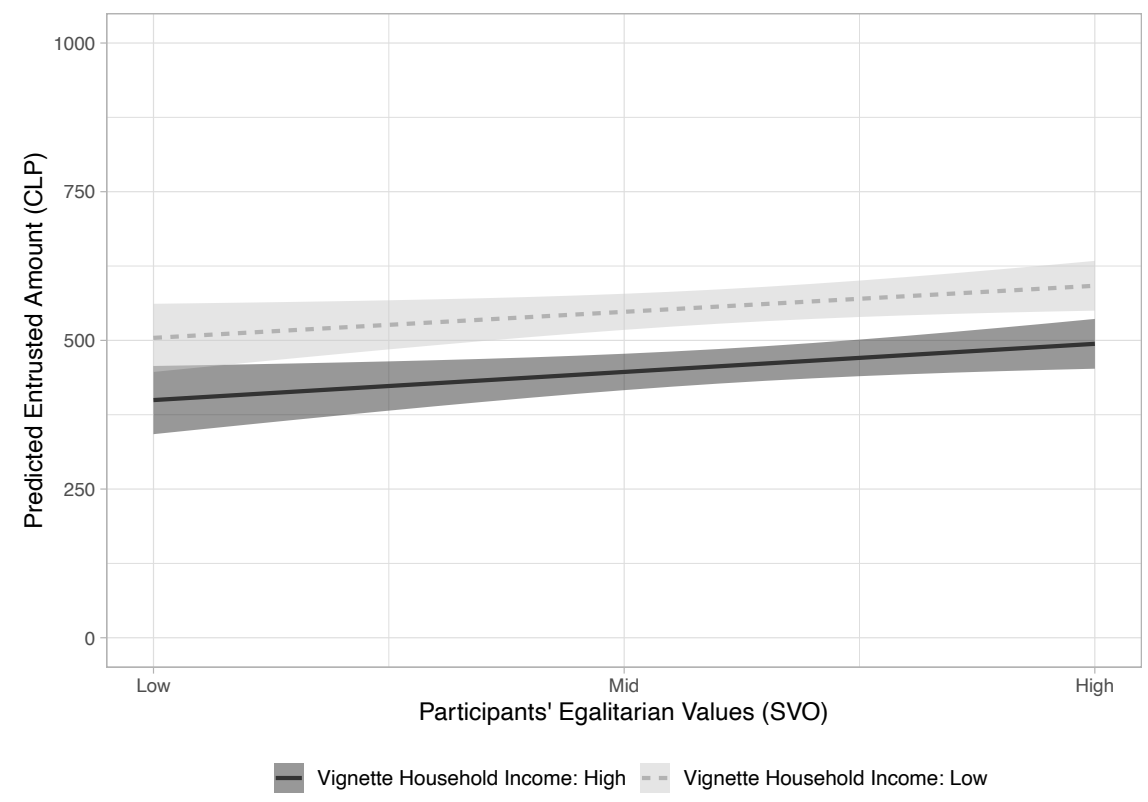

Figure 5. Predicted amount entrusted, based on vignettes' household income and participants' social values orientation. Estimated from Model 3 in Table 2. Lines represent point estimates. Shaded areas represent $95 \%$ confidence intervals.

Finally, none of the characteristics of the photographs had a discernible effect on expected trustworthiness. Neither skin pigmentation, functional features or SES categorization were significantly related to the amounts sent (see Appendix 3). Unlike previous research (Buchan et al., 2008) we found no differences in the amounts of money sent by participants or in the amounts received by vignette-trustees due to their gender. Thus, the analyses do not indicate that gender, as a diffuse status characteristic, influenced the amount sent by participants in the game.

\section{Discussion and Conclusions}

Using an original experimental survey and a lab-in-the-field approach, this study addressed the expectations of trustworthiness in cross-status interactions with strangers in a non-WEIRD and high inequality context. Findings show that, in trusting others, higher-status individuals are considered less trustworthy than lower-status individuals, even though they show higher levels of generalized trust. Thus, higher-status individuals declared more generalized trust, although on average they were deemed less trustworthy by others. This pattern is explained mainly by the lack of trust towards higher-status individuals by lower-status individuals: lower-status individuals showed ingroup favoritism, whereas higher-status individuals tended to trust others regardless of their social standing. That is, we found higher levels of relational or particularized trust (Fiske et al., 2012) in people of lower social status compared to those of higher social status. We also studied and ruled out the possibility that the egalitarian/altruistic preferences of participants explained these results: although poorer (richer) vignettes tended to receive more (less) money, this pattern was observed regardless of the social orientation values of participants.

Social psychologists have characterized the socio-cognitive tendencies of lower-status individuals as contextualist: their harsher living conditions make them prone to heightened interdependence and attunement to the needs and emotions of others (Kraus et al., 2012), and also to greater concern and caution regarding the intentions of others toward them (Kraus et al., 2011). Thus, they trust those 
who share relationships or similar characteristics more, and distrust higher-status individuals, which is supported by our results. Relational trust among lower-status individuals can also be explained by the related uncertainty identity-theory (Hogg, 2015; Navarro-Carrillo et al., 2018), in which feelings of uncertainty caused by poverty can be overcome through self-categorization as a member of a certain group and the consequent unfolding of different processes of depersonalization, such as ingroup favoritism in trusting others: lower-status individuals view others endowed with status-specific markers not as idiosyncratic individuals (hence, less predictable), but as embodiments of their respective status groups. These socio-cognitive mechanisms might explain why lower-status participants in our study tended to trust others of similar status.

By expanding research on trust beyond WEIRD societies, where most research has been conducted, our results are important because they suggest differences in how status shapes trust across societies, and also highlight cross-cultural variations in the heuristics individuals use to form their expectations of trustworthiness. We explore some implications and potential mechanisms explaining our two main findings.

The first result documented here - i.e., the greater levels of relational trust found among participants of lower social status - indicates that this regularity is not restricted to developed societies; it is also observed in Chile, a developing country characterized by high inequality and low levels of generalized trust. Therefore, relational trust might be an adaptive response (Wang \& Li, 2020) of lower-status individuals to the risks of deception in deciding who they can trust in any society. This finding also contradicts recent research. In a series of studies in which income inequality was manipulated, Samson (2018) showed that higher-status individuals tended to be seen as more trustworthy, even by lower-status individuals. Samson linked this pattern of trustworthiness to ideological mechanisms of sustaining social inequalities that secure the position of advantaged groups. The results presented here point to a different conclusion: in contexts of long-standing inequality, higher-income individuals are perceived as less trustworthy. This heuristic might be strengthened by social class stereotypes, in which the poor see those with higher income as untrustworthy because of their competence to enact their self-serving or exploitative intents (Fiske et al., 2012). These class stereotypes are more likely to appear in highly unequal and segregated contexts, like the Chilean one, in which feelings of undeserved deprivations in comparison to others reinforce grievances and motivate collective action (Power et al., 2020). Indeed, these collective grievances have brought about different large-scale social movements, protests and unrest since 2006 in Chile, a period characterized as 'the social awakening' of Chilean civil society (Garcés, 2012). Also, in Chile, a series of scandals involving the economic, political, military, and religious elites in the last few decades has translated into historically low levels of trust towards elites and institutions, particularly among lower-status groups (Somma et al., 2020). All in all, our finding fits more parsimoniously with the rising inequality observed in many developed countries and its deleterious consequences for the social fabric (Elgar \& Aitken, 2011; Putnam, 2001; Uslaner \& Brown, 2005).

The second result documented here - i.e., the importance of the household income of trustees in triggering trusting behavior among lower-status individuals - shows that not all status markers are important in forming expectations of trustworthiness across status groups. We documented that the household-income level of trustees outweighed the other status cues we manipulated in this study. Social status is a multidimensional phenomenon, and previous research has shown that not all of these dimensions affect personal dispositions similarly (Navarro-Carrillo et al., 2020; Trautmann et al., 2013). Nonetheless, the effect of income on trustworthiness has been documented (Ermisch \& Gambetta, 2016), and in line with previous research indicating that the poor are more attuned to the economic dimensions of everyday experiences (Shah et al., 2018), it seems that household income is, for them, a more meaningful status cue in risky economic exchanges. Another implication of this finding is that income differences might not only have causal effects on the trusting behavior of lower status individuals, but these differences can also strengthen their ingroup bonds, which in turn might weaken their social and economic opportunities with outgroup individuals. When income levels are 
salient in cross-status interactions (for instance, poor-students attending rich schools or affluent campuses), the two participants might puzzle each other at best and frustrate each other at worst: one person will come across as trusting and entitled, the other as inhibited and untrusting. The ingroup favoritism among lower-status individuals might thus undermine societal-level trust.

Our results also highlight the importance of cross-cultural variation in expectations of trustworthiness. For instance, it is worth mentioning the negligible statistical effect of the presentation-based status feature, which made phenotypic traits, such as skin pigmentation, explicit. This result might be explained by the particularities of the Latin American societies in which this study was carried out. Although skin pigmentation is a powerful cue for status categorization and provides differential access to social opportunities in Latin America (Bonilla-Silva, 2020; Telles, 2014), it is not as informative about the 'moral worth' of the person viewing it as it is in North America. Experimental research in the United States has documented racial disparities (between blacks and whites) in evaluations of trustworthiness due to implicit racial attitudes (Stanley et al., 2011). However, in our study, the presentation-based status and skin pigmentation of trustees had a negligible and non-significant effect on trustors' expectations of trustworthiness. We believe this is the case because racial traits in Chile are not informative of moral worth, as in other latitudes (Lamont 2002). Indeed, research conducted in Chile has demonstrated that, although whiteness is used as a cue for status attribution, the skin color of individuals was not linked to judgments of their normative behavior (Salgado \& Castillo, 2018). In Latin America in general, and in Chile in particular, class segregation is more acute than racial segregation, so people (particularly middle-class groups) with different racial traits coexist in many geographical and organizational units. The higher phenotypic variance in these social spaces might provide the subjective experiences that weaken the link between racial traits (e.g., skin pigmentation) and expectations of trustworthiness.

Unlike presentation-based features, past behavior in collective action (such as voting) seems to be robustly associated with expectations of trustworthiness, which could be interpreted as a general indicator of prosocial behavior. Indeed, voting seems to work as a signal of prosocial preferences and willingness to contribute to collective action (Aytimur et al., 2014), which might be particularly salient among the student-age population, which has the lowest turnout rate in Chilean elections (Mackenna, 2015). However, the electoral behavior of participants did not correlate with their trusting behavior, which produces an interesting ambivalence for further empirical research. Although 'the paradox of voting' has received much attention in the social sciences, the paradox of valuing the act of voting in others (as a sign of prosocial inclinations) but not in oneself, seems to be worthy of further empirical exploration.

Nonetheless, the results may also be partially explained by some limitations of the study. For instance, household income might be outweighing other vignette features due to anchoring effects: individuals might rely primarily on income as a focal interpretative heuristic to produce trustworthiness expectations, paying less attention to other informational cues, especially in an experimental setting. However, since the family incomes of others are often not directly observable in many real-world interactions, individuals may then rely on other information associated with SES to infer the socioeconomic background and trustworthiness of others. Previous research has already explored the role that visible cues of socioeconomic status, race, and ethnicity play in affecting our behavior towards others (Wacquant, 2008). Our data does not enable testing this conjecture - because both visible and non-visible traits were available for participants -, but further studies could clarify this claim. Similarly, although we argue that post-secondary education in Chile provides a privileged setting for studying social expectations based on class, further research in other populations and settings is required to generalize our findings.

\section{Acknowledgments}


We would like to thank Dr. Juan Carlos Oyanedel, who participated in the early stages of this research, and the two anonymous reviewers of Social Science Research for their valuable comments. An earlier version was presented at the $11^{\text {th }}$ Annual Conference of the International Network of Analytical Sociologists at Stanford University in 2018. Any errors are the authors' own responsibility.

\section{Funding}

This paper was funded by The National Research and Development Agency (ANID), Chilean Ministry of Science, Technology, Knowledge and Innovation, through its programs The National Fund for Scientific and Technological Development (FONDECYT 1161624), and through the Centre for Research in Inclusive Education (SCIA ANID CIE160009).

\section{References}

Algan, Y., \& Cahuc, P. (2014). Trust, Growth, and Well-Being: New Evidence and Policy Implications. In P. Aghion \& S. Durlauf (Eds.), Handbook of Economic Growth (Vol. 2, pp. 49120). Elsevier. https://ideas.repec.org/h/eee/grochp/2-49.html

American Psychological Association. (2017). Ethical Principles of Psychologists and Code of Conduct. American Psychological Association; https://www.apa.org/ethics/code\#807. https://www.apa.org/ethics/code\#807

American Sociological Association. (2018). Code of Ethics (p. 21). American Sociological Association. http://www.asanet.org/sites/default/files/asa_code_of_ethics-june2018.pdf

Ashraf, N., Bohnet, I., \& Piankov, N. (2006). Decomposing trust and trustworthiness. Experimental Economics, 9(3), 193-208. https://doi.org/10.1007/s10683-006-9122-4

Atzmüller, C., \& Steiner, P. M. (2010). Experimental Vignette Studies in Survey Research. Methodology, 6(3), 128-138. https://doi.org/10.1027/1614-2241/a000014

Auspurg, K., \& Hinz, T. (2014). Factorial Survey Experiments. SAGE Publications.

Aytimur, R. E., Boukouras, A., \& Schwager, R. (2014). Voting as a signaling device. Economic Theory, 55(3), 753-777. https://doi.org/10.1007/s00199-013-0764-0

Balliet, D., Parks, C., \& Joireman, J. (2009). Social Value Orientation and Cooperation in Social Dilemmas: A Meta-Analysis. Group Processes \& Intergroup Relations, 12(4), 533-547. https://doi.org/10.1177/1368430209105040

Ben-Ner, A., \& Halldorsson, F. (2010). Trusting and trustworthiness: What are they, how to measure them, and what affects them. Journal of Economic Psychology, 31(1), 64-79. https://doi.org/10.1016/j.joep.2009.10.001

Berg, J., Dickhaut, J., \& McCabe, K. (1995). Trust, Reciprocity, and Social History. Games and Economic Behavior, 10(1), 122-142. https://doi.org/10.1006/game.1995.1027

Berger, J., \& Fişek, M. H. (2006). Diffuse Status Characteristics and the Spread of Status Value: A Formal Theory. American Journal of Sociology, 111(4), 1038-1079. https://doi.org/10.1086/498633

Bonilla-Silva, E. (2020). ¿Aquí no hay racismo? Apuntes Preliminares Sobre Lo Racial en Las Américas. Revista de Humanidades, 42(Julio-Diciembre), 425-443.

Buchan, N. R., Croson, R. T., \& Solnick, S. (2008). Trust and gender: An examination of behavior and beliefs in the Investment Game. Journal of Economic Behavior \& Organization, 68(3-4), 466476.

Buskens, V., \& Weesie, J. (2000). An Experiment on the Effects of Embeddedness in Trust Situations: Buying a Used Car. Rationality and Society, 12(2), 227-253. https://doi.org/10.1177/104346300012002004

Cabrera, F.-J. (2016). La influencia del capital socioeconómico y cultural en el acceso a las instituciones de educación superior en Chile. Estudios Sociológicos, 34(100), 107-143.

Chen, D. L., Schonger, M., \& Wickens, C. (2016). oTree-An open-source platform for laboratory, online, and field experiments. Journal of Behavioral and Experimental Finance, 9, 88-97. https://doi.org/10.1016/j.jbef.2015.12.001 
Chilean Ministry of Social Development. (2017). Encuesta de Caracterización Socioeconómica Nacional (CASEN) 2017 [National Socioeconomic Characterization Survey 2017]. http://observatorio.ministeriodesarrollosocial.gob.cl

Coleman, J. S. (1990). Foundations of Social Theory. Harvard University Press.

Dohmen, T., Falk, A., Huffman, D., Sunde, U., Schupp, J., \& Wagner, G. G. (2011). Individual Risk Attitudes: Measurement, Determinants, and Behavioral Consequences. Journal of the European Economic Association, 9(3), 522-550. https://doi.org/10.1111/j.1542-4774.2011.01015.x

Dülmer, H. (2007). Experimental Plans in Factorial Surveys: Random or Quota Design? Sociological Methods \& Research, 35(3), 382-409. https://doi.org/10.1177/0049124106292367

Eagly, A. H. (2009). The his and hers of prosocial behavior: An examination of the social psychology of gender. American Psychologist, 64(8), 644. https://doi.org/10.1037/0003-066X.64.8.644

Elgar, F. J., \& Aitken, N. (2011). Income inequality, trust and homicide in 33 countries. European Journal of Public Health, 21(2), 241-246. https://doi.org/10.1093/eurpub/ckq068

Ermisch, J., \& Gambetta, D. (2016). Income and Trustworthiness. Sociological Science, 3, 710-729. https://doi.org/10.15195/v3.a30

Ermisch, J., Gambetta, D., Laurie, H., Siedler, T., \& Noah Uhrig, S. C. (2009). Measuring people's trust. Journal of the Royal Statistical Society: Series A (Statistics in Society), 172(4), 749-769. https://doi.org/10.1111/j.1467-985X.2009.00591.x

Espinoza, V., \& Núñez, J. (2014). Movilidad Ocupacional en Chile 2001-2009 ¿Desigualdad de ingresos con igualdad de oportunidades? Revista Internacional de Sociología, 72(1), 57-82. https://doi.org/10.3989/ris.2011.11.08

Fairbrother, M., \& Martin, I. W. (2013). Does inequality erode social trust? Results from multilevel models of US states and counties. Social Science Research, 42(2), 347-360. https://doi.org/10.1016/j.ssresearch.2012.09.008

Fiddick, L., \& Cummins, D. (2007). Are perceptions of fairness relationship-specific? The case of noblesse oblige. The Quarterly Journal of Experimental Psychology, 60(1), 16-31. https://doi.org/10.1080/17470210600577266

Fişek, M. H., Berger, J., \& Norman, R. Z. (2005). Status cues and the formation of expectations. Social Science Research, 34(1), 80-102. https://doi.org/10.1016/j.ssresearch.2003.10.004

Fiske, S. T., Moya, M., Russell, A. M., \& Bearns, C. (2012). The Secret Handshake: Trust in CrossClass Encounters. In S. T. Fiske \& H. R. Markus (Eds.), Facing Social Class: How Societal Rank Influences Interaction (pp. 234-252). Russell Sage Foundation.

Garcés, M. (2012). El despertar de la sociedad: Los movimientos sociales de América Latina y Chile. LOM Ediciones.

Gelman, A., \& Hill, J. (2006). Data Analysis Using Regression and Multilevel/Hierarcbical Models. Cambridge University Press.

Goffman, E. (1959). The Presentation of Self in Everyday Life. Doubleday.

Granovetter, M. (1973). The Strength of Weak Ties. American Journal of Sociology, 78(6), 1360-1380. https://doi.org/10.2307/2776392

Hardin, R. (2002). Trust and Trustworthiness. Russell Sage Foundation.

Hogg, M. A. (2015). To belong or not to belong: Some self-conceptual and behavioural consequences of identity uncertainty. Revista de Psicologia Social, 30(3), 586-613. https://doi.org/10.1080/02134748.2015.1065090

International Labour Organization. (2012). International Standard Classification of Occupations 2008 (ISCO08): Structure, group definitions and correspondence tables. http://www.ilo.org/global/publications/ilo-bookstore/orderonline/books/WCMS_172572/lang--en/index.htm

Johnson, N. D., \& Mislin, A. (2012). How much should we trust the World Values Survey trust question? Economics Letters, 116(2), 210-212. https://doi.org/10.1016/j.econlet.2012.02.010

Kraus, M. W., Horberg, E. J., Goetz, J. L., \& Keltner, D. (2011). Social Class Rank, Threat Vigilance, and Hostile Reactivity. Personality and Social Psychology Bulletin, 37(10), 1376-1388. https://doi.org/10.1177/0146167211410987

Kraus, M. W., Piff, P. K., Mendoza-Denton, R., Rheinschmidt, M. L., \& Keltner, D. (2012). Social class, solipsism, and contextualism: How the rich are different from the poor. Psychological Review, 119(3), 546-572. https://doi.org/10.1037/a0028756 
Lamont, M. (2002). The Dignity of Working Men: Morality and the Boundaries of Race, Class, and Immigration. Harvard University Press.

Lei, V., \& Vesely, F. (2010). In-Group versus Out-Group Trust: The Impact of Income Inequality. Southern Economic Joumal, 76(4), 1049-1063. JSTOR.

Lundmark, S., Gilljam, M., \& Dahlberg, S. (2016). Measuring Generalized Trust: An Examination of Question Wording and the Number of Scale Points. Public Opinion Quarterly, 80(1), 26-43. https://doi.org/10.1093/poq/nfv042

Mackenna, B. (2015). Composición del electorado en elecciones con voto obligatorio y voluntario: Un estudio cuasi-experimental de la participación electoral en Chile. Revista Latinoamericana de Opinión Pública, 5(1), 49-97.

McKnight, D. H., \& Chervany, N. L. (2006). Reflections on an Initial Trust Building Model. In R. Bachmann \& A. Zaheer (Eds.), Handbook of Trust Research (pp. 29-51). Edward Elgar Publishing.

Navarro-Carrillo, G., Alonso-Ferres, M., Moya, M., \& Valor-Segura, I. (2020). Socioeconomic Status and Psychological Well-Being: Revisiting the Role of Subjective Socioeconomic Status. Frontiers in Psychology, 11. https://doi.org/10.3389/fpsyg.2020.01303

Navarro-Carrillo, G., Valor-Segura, I., \& Moya, M. (2018). Do you Trust Strangers, Close Acquaintances, and Members of Your Ingroup? Differences in Trust Based on Social Class in Spain. Social Indicators Research, 135(2), 585-597. https://doi.org/10.1007/s11205-016$1527-7$

Núñez, J., \& Miranda, L. (2010). Intergenerational Income Mobility in a Less-Developed, HighInequality Context: The Case of Chile. The B.E. Journal of Economic Analysis \& Policy, 10(1), 33. https://doi.org/10.2202/1935-1682.2339

Oosterhof, N. N., \& Todorov, A. (2008). The functional basis of face evaluation. Proceedings of the National Academy of Sciences, 105(32), 11087-11092. https://doi.org/10.1073/pnas.0805664105

Ostrom, E. (1998). A behavioral approach to the rational choice theory of collective action: Presidential address, American Political Science Association, 1997. American Political Science Review, 92(1), 1-22.

Piff, P. K., Kraus, M. W., Côté, S., Cheng, B. H., \& Keltner, D. (2010). Having less, giving more: The influence of social class on prosocial behavior. Journal of Personality and Social Psychology, 99(5), 771-784. https://doi.org/10.1037/a0020092

PNUD. (2017). Desiguales. Origenes, Cambios y Desafios de la Brecha Social en Cbile. Uqbar Editores.

Power, S. A., Madsen, T., \& Morton, T. A. (2020). Relative deprivation and revolt: Current and future directions. Current Opinion in Psychology, 35, 119-124. https://doi.org/10.1016/j.copsyc.2020.06.010

Putnam, R. D. (2001). Bowling Alone: The Collapse and Revival of American Community. Simon \& Schuster Ltd.

Raftery, A. E. (1995). Bayesian model selection in social research. Sociological Methodology, 25, 111-163.

Robbins, B. G. (2016a). What is Trust? A Multidisciplinary Review, Critique, and Synthesis. Sociology Compass, 10(10), 972-986. https://doi.org/10.1111/soc4.12391

Robbins, B. G. (2016b). From the general to the specific: How social trust motivates relational trust. Social Science Research, 55, 16-30. https://doi.org/10.1016/j.ssresearch.2015.09.004

Robbins, B. G. (2017). Status, identity, and ability in the formation of trust. Rationality and Society, 29(4), 408-448. https://doi.org/10.1177/1043463117734179

Rousseau, D. M., Sitkin, S. B., Burt, R. S., \& Camerer, C. (1998). Not So Different After All: A CrossDiscipline View Of Trust. Academy of Management Review, 23(3), 393-404. https://doi.org/10.5465/amr.1998.926617

Salgado, M. (2018). Gender-Biased Expectations of Altruism in Adolescents. Frontiers in Psychology, 9(484), 1-11. https://doi.org/10.3389/fpsyg.2018.00484

Salgado, M. (2020). Adolescents' Justice Evaluations of Earning Gaps in an Unequal Country: Evidence from Chile. Young, 28(3), 294-314. https://doi.org/10.1177/1103308819886467

Salgado, M., \& Castillo, J. (2018). Differential status evaluations and racial bias in the Chilean segregated school system. Sociological Forum, 33(2), 354-377. https://doi.org/10.1111/socf.12426 
Samson, K. (2018). Trust as a mechanism of system justification. PLOS ONE, 13(10), e0205566. https://doi.org/10.1371/journal.pone.0205566

Samson, K., \& Zaleskiewicz, T. (2019). Social class and interpersonal trust: Partner's warmth, external threats and interpretations of trust betrayal. European Journal of Social Psychology, $n / a(\mathrm{n} / \mathrm{a})$. https://doi.org/10.1002/ejsp.2648

Sapienza, P., Toldra-Simats, A., \& Zingales, L. (2013). Understanding Trust. The Economic Journal, 123(573), 1313-1332. https://doi.org/10.1111/ecoj.12036

Shah, A. K., Zhao, J., Mullainathan, S., \& Shafir, E. (2018). Money in the Mental Lives of the Poor. Social Cognition, 36(1), 4-19. https://doi.org/10.1521/soco.2018.36.1.4

Simpson, B., McGrimmon, T., \& Irwin, K. (2007). Are Blacks Really Less Trusting than Whites? Revisiting the Race and Trust Question. Social Forces, 86(2), 525-552. https://doi.org/10.1093/sf/86.2.525

Snijders, T. A. B., \& Bosker, R. J. (1994). Modeled Variance in Two-Level Models. Sociological Methods \& Research, 22(3), 342-363. https://doi.org/10.1177/0049124194022003004

Somma, N. M., Bargsted, M., Pavlic, R. D., \& Medel, R. M. (2020). No water in the oasis: The Chilean Spring of 2019-2020. Social Movement Studies, O(0), 1-8. https://doi.org/10.1080/14742837.2020.1727737

Stanley, D. A., Sokol-Hessner, P., Banaji, M. R., \& Phelps, E. A. (2011). Implicit race attitudes predict trustworthiness judgments and economic trust decisions. Proceedings of the National Academy of Sciences, 108(19), 7710-7715. https://doi.org/10.1073/pnas.1014345108

Starmans, C., Sheskin, M., \& Bloom, P. (2017). Why people prefer unequal societies. Nature Human Behaviour, 1, 0082. https://doi.org/10.1038/s41562-017-0082

Stellar, J. E., Manzo, V. M., Kraus, M. W., \& Keltner, D. (2012). Class and compassion: Socioeconomic factors predict responses to suffering. Emotion, 12(3), 449.

Tan, J. H. W., \& Vogel, C. (2008). Religion and trust: An experimental study. Journal of Economic Psychology, 29(6), 832-848. https://doi.org/10.1016/j.joep.2008.03.002

Telles, E. (2014). Pigmentocracies: Ethnicity, Race, and Color in Latin America. UNC Press Books.

The World Bank. (2017). World Development Indicators. https://data.worldbank.org

Thumala Olave, M. A. (2012). The aristocracy of the will: A critique of Pierre Bourdieu with illustrations from Chile. Social Compass, 59(1), 52-68. https://doi.org/10.1177/0037768611432126

Torche, F. (2005). Unequal But Fluid: Social Mobility in Chile in Comparative Perspective. American Sociological Review, 70(3), 422-450. https://doi.org/10.1177/000312240507000304

Torres, F., Salgado, M., Mackenna, B., \& Núñez, J. (2019). Who Differentiates by Skin Color? Status Attributions and Skin Pigmentation in Chile. Frontiers in Psychology, 10. https://doi.org/10.3389/fpsyg.2019.01516

Trautmann, S. T., Kuilen, G. van de, \& Zeckhauser, R. J. (2013). Social Class and (Un)Ethical Behavior A Framework, With Evidence From a Large Population Sample. Perspectives on Psychological Science, 8(5), 487-497. https://doi.org/10.1177/1745691613491272

Tropp, L. R., Stout, A. M., Boatswain, C., Wright, S. C., \& Pettigrew, T. F. (2006). Trust and Acceptance in Response to References to Group Membership: Minority and Majority Perspectives on Cross-Group Interactions1. Journal of Applied Social Psychology, 36(3), 769-794. https://doi.org/10.1111/j.0021-9029.2006.00031.x

Uslaner, E. M. (2000). Producing and consuming trust. Political Science Quarterly, 115(4), 569-590.

Uslaner, E. M., \& Brown, M. (2005). Inequality, Trust, and Civic Engagement. American Politics Research, 33(6), 868-894. https://doi.org/10.1177/1532673X04271903

Valenzuela, J. P., Bellei, C., \& Ríos, D. de los. (2014). Socioeconomic school segregation in a marketoriented educational system. The case of Chile. Journal of Education Policy, 29(2), 217-241. https://doi.org/10.1080/02680939.2013.806995

Wacquant, L. (2008). Urban Outcasts: A Comparative Sociology of Advanced Marginality. Polity.

Wang, Y., \& Li, L. M. W. (2020). Does your trust in strangers or close acquaintances promote better health? Societal residential mobility matters. The Journal of Social Psychology, 160(4), 416-427. https://doi.org/10.1080/00224545.2019.1658569

Wheeler, B. (2019). Package 'AlgDesign' [R]. https://cran.rproject.org/web/packages/AlgDesign/AlgDesign.pdf 
Yamagishi, T., Cook, K. S., \& Watabe, M. (1998). Uncertainty, Trust, and Commitment Formation in the United States and Japan. American Journal of Sociology, 104(1), 165-194. https://doi.org/10.1086/210005

Zmerli, S., \& Castillo, J. C. (2015). Income inequality, distributive fairness and political trust in Latin America. Social Science Research, 52, 179-192. https://doi.org/10.1016/j.ssresearch.2015.02.003 


\section{Appendix}

Appendix 1. Photograph evaluation descriptive statistics.

\begin{tabular}{clccc}
\hline \hline Source & \multicolumn{1}{c}{ Variable } & Mean & SD & Range \\
\hline \hline & Skin pigmentation (PERLA) & 2.83 & 0.94 & {$[1-11]$} \\
& Generosity & 5.54 & 0.65 & {$[1-10]$} \\
& Trustworthiness & 5.38 & 0.66 & {$[1-10]$} \\
Photograph & Attractiveness & 4.01 & 0.97 & {$[1-10]$} \\
Evaluations & Submission & 4.54 & 0.80 & {$[1-10]$} \\
& Intelligence & 6.00 & 0.64 & {$[1-10]$} \\
& Subjective Status & 5.66 & 1.17 & {$[1-10]$} \\
& Objective Status & 1.78 & 0.65 & {$[0-3]$} \\
\hline \hline
\end{tabular}

Appendix 2. Participant survey response descriptive statistics.

\begin{tabular}{|c|c|c|c|c|c|c|c|c|c|c|c|}
\hline \multirow{2}{*}{$\begin{array}{l}\text { Institution } \\
\text { Variable }\end{array}$} & \multicolumn{2}{|c|}{ All } & \multicolumn{2}{|c|}{ Vocational } & \multicolumn{2}{|c|}{ Technical } & \multicolumn{2}{|c|}{ University B } & \multicolumn{2}{|c|}{ University A } & \multirow[b]{2}{*}{ Range } \\
\hline & Mean & $\mathrm{SD}$ & Mean & SD & Mean & $\mathrm{SD}$ & Mean & SD. & Mean & $\mathrm{SD}$ & \\
\hline Gender: Female & 0.54 & - & 0.80 & - & 0.38 & - & 0.57 & - & 0.40 & - & {$[0-1]$} \\
\hline Age & 21.69 & 2.73 & 23.35 & 3.32 & 21.38 & 2.53 & 20.75 & 1.71 & 21.27 & 2.43 & {$[17-35]$} \\
\hline Parent's Education & 5.93 & 2.14 & 4.33 & 1.65 & 5.25 & 1.76 & 6.80 & 1.92 & 7.33 & 1.78 & {$[1-10]$} \\
\hline Parent's Occupation & 5.45 & 2.59 & 3.42 & 2.16 & 4.68 & 2.27 & 6.65 & 2.16 & 7.05 & 1.94 & {$[1-10]$} \\
\hline Socioeconomic Status (SES) & -0.02 & 0.92 & -0.78 & 0.70 & -0.33 & 0.73 & 0.41 & 0.79 & 0.61 & 0.71 & {$[-1.8-1.8]$} \\
\hline Religion: Catholic & 0.35 & - & 0.28 & - & 0.40 & - & 0.48 & - & 0.25 & - & {$[0-1]$} \\
\hline Religion: Evangelical & 0.20 & - & 0.43 & - & 0.15 & - & 0.15 & - & 0.05 & - & {$[0-1]$} \\
\hline Religion: Other & 0.05 & - & 0.10 & - & 0.02 & - & 0.02 & - & 0.05 & - & {$[0-1]$} \\
\hline Religion: None & 0.40 & - & 0.18 & - & 0.43 & - & 0.35 & - & 0.65 & - & {$[0-1]$} \\
\hline Electoral Participation & 0.44 & 0.50 & 0.52 & 0.50 & 0.47 & 0.50 & 0.45 & 0.50 & 0.32 & 0.47 & {$[0-1]$} \\
\hline Generalized Trust & 4.53 & 2.41 & 4.13 & 2.51 & 3.70 & 2.44 & 4.95 & 2.09 & 5.33 & 2.28 & {$[0-10]$} \\
\hline Risk Attitude & 7.09 & 1.79 & 6.42 & 2.02 & 7.68 & 1.57 & 7.75 & 1.45 & 6.52 & 1.68 & {$[1-10]$} \\
\hline Social Values Orientation (SVO) & 0.62 & 0.38 & 0.57 & 0.37 & 0.56 & 0.36 & 0.60 & 0.39 & 0.76 & 0.35 & {$[0-1]$} \\
\hline
\end{tabular}


Appendix 3. Complete multi-level regression models of trusted amount in vignette experiment.

\begin{tabular}{|c|c|c|c|c|c|c|c|}
\hline \multicolumn{2}{|r|}{ Model } & \multicolumn{2}{|c|}{ (1) } & \multicolumn{2}{|c|}{ (2) } & \multicolumn{2}{|c|}{ (3) } \\
\hline Source & Variable & Coef. & (SE) & Coef. & $(\mathrm{SE})$ & Coef. & (SE) \\
\hline \multirow{17}{*}{$\begin{array}{c}\text { Vignette: } \\
\text { Trustee } \\
\text { Level }\end{array}$} & Photo Edu: Technic & -12.326 & $(10.143)$ & -10.593 & (10.096) & -12.488 & $(10.129)$ \\
\hline & Photo Edu: Univ. B & -18.150 & $(9.733)$ & -17.641 & (9.685) & -18.247 & $(9.723)$ \\
\hline & Photo Edu: Univ. A & -5.510 & $(10.185)$ & -3.997 & $(10.134)$ & -6.248 & $(10.174)$ \\
\hline & Home Edu: High school & 2.736 & $(11.491)$ & 2.875 & $(11.428)$ & 2.565 & $(11.475)$ \\
\hline & Home Edu: Technic & -13.103 & $(11.772)$ & -12.100 & (11.711) & -13.456 & $(11.757)$ \\
\hline & Home Edu: Univ. B & -22.433 & $(11.751)$ & -21.649 & $(11.688)$ & -22.489 & $(11.732)$ \\
\hline & Home Edu: Univ. A & -6.433 & $(12.479)$ & -5.682 & $(12.416)$ & -6.545 & $(12.463)$ \\
\hline & Home Income: Mid-Low & $-43.421 * *$ & $(12.024)$ & $-42.935^{* *}$ & $(11.958)$ & $-53.159 *$ & $(22.035)$ \\
\hline & Home Income: Mid & $-42.656 * *$ & $(12.562)$ & $-42.714 * *$ & $(12.495)$ & -16.479 & $(21.931)$ \\
\hline & Home Income: Mid-High & $-110.722 * *$ & $(11.156)$ & $-109.973 * *$ & $(11.096)$ & $-128.486 * *$ & $(20.844)$ \\
\hline & Home Income: High & $-143.569 * *$ & $(12.197)$ & $-142.814 * *$ & $(12.130)$ & $-157.762 * *$ & $(21.987)$ \\
\hline & Religion: Evangelical & 10.713 & $(9.013)$ & 11.447 & $(8.970)$ & 10.716 & $(8.999)$ \\
\hline & Religion: None & -11.892 & $(8.352)$ & -11.697 & $(8.307)$ & -12.021 & $(8.340)$ \\
\hline & Gender: Female & -4.753 & $(18.420)$ & -4.205 & $(18.318)$ & -4.628 & $(18.393)$ \\
\hline & Electoral Participation & $29.653^{* *}$ & (7.404) & $28.887^{* *}$ & $(7.366)$ & $29.965^{* *}$ & $(7.395)$ \\
\hline & Social Status: Mid & -29.237 & $(48.515)$ & -25.107 & $(48.265)$ & -30.624 & $(48.449)$ \\
\hline & Social Status: Low & -103.920 & $(126.848)$ & -89.978 & $(126.229)$ & -107.627 & $(126.676)$ \\
\hline \multirow{8}{*}{$\begin{array}{l}\text { Photograph } \\
\text { Evaluation }\end{array}$} & Skin Color & 7.241 & $(7.867)$ & 7.724 & $(7.825)$ & 7.259 & $(7.856)$ \\
\hline & Generosity & 24.728 & (20.813) & 25.361 & $(20.696)$ & 24.841 & $(20.784)$ \\
\hline & Trustworthiness & -42.022 & (32.103) & -42.915 & $(31.935)$ & -41.623 & $(32.063)$ \\
\hline & Attractiveness' & 21.805 & (14.954) & 21.277 & $(14.874)$ & 21.432 & (14.933) \\
\hline & Submission & 11.989 & (13.668) & 12.365 & (13.593) & 11.743 & $(13.648)$ \\
\hline & Intelligence & 17.039 & (18.698) & 17.416 & $(18.597)$ & 16.992 & $(18.673)$ \\
\hline & Subjective Status & -32.294 & $(28.045)$ & -33.426 & $(27.887)$ & -32.655 & $(28.003)$ \\
\hline & Objective Status & 112.472 & $(75.655)$ & 106.394 & $(75.286)$ & 115.991 & $(75.553)$ \\
\hline \multirow{10}{*}{$\begin{array}{l}\text { Participant } \\
\text { Responses }\end{array}$} & Gender: Female & 10.682 & $(29.670)$ & 10.955 & $(29.591)$ & 10.436 & $(29.706)$ \\
\hline & Age & 7.892 & $(5.331)$ & 7.780 & $(5.317)$ & 7.873 & $(5.338)$ \\
\hline & Socioeconomic Status (SES) & 6.440 & $(18.092)$ & -29.088 & $(19.540)$ & 6.186 & $(18.114)$ \\
\hline & Religion: Evangelical & 52.064 & $(38.665)$ & 53.235 & $(38.562)$ & 52.991 & $(38.712)$ \\
\hline & Religion: Other & -3.516 & $(64.976)$ & -1.321 & $(64.806)$ & -3.538 & $(65.059)$ \\
\hline & Religion: None & 41.117 & $(30.699)$ & 41.380 & $(30.617)$ & 41.736 & $(30.737)$ \\
\hline & Electoral Participation & 15.221 & $(26.357)$ & 14.475 & $(26.287)$ & 14.818 & $(26.390)$ \\
\hline & Generalized Trust & $27.214^{* *}$ & $(5.919)$ & $27.351 * *$ & $(5.903)$ & $27.327 * *$ & $(5.926)$ \\
\hline & Generalized Risk & $24.189 * *$ & $(7.929)$ & $23.976^{* *}$ & $(7.908)$ & $24.215^{* *}$ & $(7.938)$ \\
\hline & Social Values Orientation (SVO) & $76.900^{*}$ & $(36.194)$ & $75.982 *$ & $(36.097)$ & 71.788 & $(40.794)$ \\
\hline \multirow{4}{*}{ Design } & Ins: Technic & -44.249 & $(42.012)$ & -44.616 & $(41.899)$ & -44.294 & $(42.061)$ \\
\hline & Ins: Univ. B & -3.068 & $(45.422)$ & -3.905 & $(45.301)$ & -2.696 & $(45.475)$ \\
\hline & Ins: Univ. A & 13.853 & $(48.306)$ & 12.239 & $(48.181)$ & 14.161 & $(48.362)$ \\
\hline & Promise & $-83.618^{* *}$ & $(27.223)$ & $-84.795^{* *}$ & $(27.151)$ & $-83.760 * *$ & $(27.258)$ \\
\hline \multirow{15}{*}{$\begin{array}{c}\text { Interaction } \\
\text { Effects }\end{array}$} & HI: Mid-Low * SES & & & $34.880 * *$ & $(12.231)$ & & \\
\hline & HI: Mid * SES & & & $30.209 *$ & (12.004) & & \\
\hline & HI: Mid-High * SES & & & $55.359 * *$ & (11.594) & & \\
\hline & HI: High $*$ SES & & & $58.416 * *$ & $(12.025)$ & & \\
\hline & HI: Mid-Low $*$ SVO & & & & & 15.839 & $(30.084)$ \\
\hline & HI: Mid * SVO & & & & & -42.113 & (29.133) \\
\hline & HI: Mid-High * SVO & & & & & 28.959 & $(28.535)$ \\
\hline & HI: High * SVO & & & & & 22.819 & $(29.588)$ \\
\hline & Intercept & -50.093 & $(208.847)$ & -37.467 & $(207.947)$ & -49.862 & $(209.128)$ \\
\hline & Evaluation-level $\mathrm{R}^{2}$ & \multicolumn{2}{|c|}{0.2041} & \multicolumn{2}{|c|}{0.2104} & \multicolumn{2}{|c|}{0.2041} \\
\hline & Participant-level $\mathrm{R}^{2}$ & \multicolumn{2}{|c|}{0.2683} & \multicolumn{2}{|c|}{0.2723} & \multicolumn{2}{|c|}{0.2666} \\
\hline & AIC & \multicolumn{2}{|c|}{38808} & \multicolumn{2}{|c|}{38784} & & \\
\hline & $\mathrm{BIC}$ & & & & & & \\
\hline & Evaluations & & & & & & \\
\hline & Participants & & & & & & \\
\hline
\end{tabular}

Notes: Unstandardized coefficients and multi-level standard errors reported (on parentheses). R ${ }^{2}$ estimated using Snijders and Bosker approach (1994). ${ }^{*} p<0.05,{ }^{* *} p<0.01$. 